STRUCTURAL BIOLOGY COMMUNICATIONS

ISSN 2053-230X

\section{An extracellular domain of the EsaA membrane component of the type VIIb secretion system: expression, purification and crystallization}

\author{
Nicole Mietrach, ${ }^{\mathrm{a}, \mathrm{b}}$ Andreas Schlosser ${ }^{\mathrm{b}}$ and Sebastian Geibel ${ }^{\mathrm{a}, \mathrm{b} *}$
}

anstitute for Molecular Infection Biology, Julius-Maximilians-University Würzburg, Josef Schneider Strasse 2, 97080 Würzburg, Germany, and ${ }^{\mathbf{b}}$ Rudolf Virchow Center for Experimental Biomedicine, Julius-Maximilians-University Würzburg, Josef Schneider Strasse 2, 97080 Würzburg, Germany. ${ }^{*}$ Correspondence e-mail:

sebastian.geibel@uni-wuerzburg.de

Edited by G. G. Privé, University of Toronto, Canada

Keywords: ESAT-6-like secretion system; ESS; type VII secretion system; EsaA; extracellular domain; Staphylococcus aureus USA300.

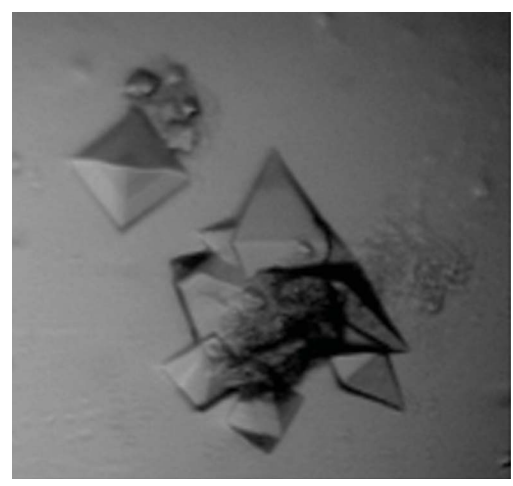

The membrane protein EsaA is a conserved component of the type VIIb secretion system. Limited proteolysis of purified EsaA from Staphylococcus aureus USA300 identified a stable $48 \mathrm{kDa}$ fragment, which was mapped by fingerprint mass spectrometry to an uncharacterized extracellular segment of EsaA. Analysis by circular dichroism spectroscopy showed that this fragment folds into a single stable domain made of mostly $\alpha$-helices with a melting point of $34.5^{\circ} \mathrm{C}$. Size-exclusion chromatography combined with multi-angle light scattering indicated the formation of a dimer of the purified extracellular domain. Octahedral crystals were grown in $0.2 \mathrm{M}$ ammonium citrate tribasic $\mathrm{pH}$ 7.0, 16\% PEG 3350 using the hanging-drop vapor-diffusion method. Diffraction data were analyzed to $4.0 \AA$ resolution, showing that the crystals belonged to the enantiomorphic tetragonal space groups $P 4_{1} 2_{1} 2$ or $P 4_{3} 2_{1} 2$, with unit-cell parameters $a=197.5, b=197.5, c=368.3 \AA$, $\alpha=\beta=\gamma=90^{\circ}$.

\section{Introduction}

Type VII secretion systems are used by a broad range of Gram-positive bacteria to secrete effector proteins across their cell walls. While type VIIa secretion systems (also termed ESX secretion systems) are found in Actinomycetes and have been linked to tuberculosis, type VIIb systems (also termed ESS secretion systems) are found in Firmicutes and have been implicated in Staphylococcus aureus infections as well as in bacterial competition (Gröschel et al., 2016). The two systems have two homologous components in common: (i) one or more effector proteins of the WXG100 protein family and (ii) an ATPase that recognizes the substrates in the cytoplasm and energizes their transport across the membrane (Unnikrishnan et al., 2017). Additional system-specific proteins are required for function. The type VIIb secretion system encodes four conserved membrane components (EssA, EssB, EssC and EsaA), which are necessary and sufficient for the secretion of effector proteins (Burts et al., 2005; Kneuper et al., 2014). Recent studies have indicated that these components form a complex embedded in the membrane, which was suggested to compose the secretion machine (Aly et al., 2017; Mielich-Süss et al., 2017). Biochemical studies have shown that two of these components (EssB and EsaA) assemble into a complex in the cell envelope (Ahmed et al., 2018), where their assembly is mediated by flotillin, a constitutent of lipid rafts (Mielich-Süss et al., 2017). The EsaA membrane component (115 kDa) is unique to type VIIb secretion systems; it is predicted to have 
Table 1

Macromolecule-production information.

\begin{tabular}{|c|c|}
\hline Source organism & S. aureus USA300 \\
\hline DNA source & Synthesized DNA, codon-optimized for $E$. coli \\
\hline $\mathrm{X} 1$ & TGGAGCCACCCGCAGT \\
\hline $\mathrm{X} 2$ & TTTTTGCCCTCGTTATCTAGATTTTGTCGA \\
\hline $\mathrm{X} 3$ & TAACGAGGGCAAAAAATGAAAAAGAAAAATTGGATTTAC \\
\hline $\mathrm{X} 4$ & GTGGCTCCAAGCGCTAATCAGGCGTTCCTTTTTGA \\
\hline $\mathrm{X} 5$ & TAACGAGGGCAAAAAATGAACAAAATCCATATCGCA \\
\hline X6 & GTGGCTCCAAGCGCTTCCACCAACCGGGTTCGACATAAAG \\
\hline $\mathrm{X} 7$ & TACTTCCAATCCGGAATGTCACAAAAAGACTCGGT \\
\hline $\mathrm{X} 8$ & TAGTTATTGCTCAGCTTATTTCGGTTCTTGCGGTT \\
\hline X9 & GCTGAGCAATAACTAGCATAAC \\
\hline $\mathrm{X} 10$ & TCCGGATTGGAAGTACAG \\
\hline Cloning vector & pET-16b, pASK-IBA3C \\
\hline Expression vector & pET-16b, pASK-IBA3C \\
\hline Expression host & E. coli BL21 Star \\
\hline Complete amino-acid sequence of HIS-TEV-esaAex_2 & $\begin{array}{l}\text { HHHHHSSGENLYFQSGMSQKDSVELDNYINALKQMDSQ IDQQSSMQDTGKEEYKQTVKENLDKLREIIQSQ } \\
\text { ESPFSKGMIEDYRKQLTESLQDELANNKDLQDALNS IKMNNAQFAENLEKQLHDDIVKEPDTDTTFIYNM } \\
\text { SKQDFIAAGLNEGEANKYEAIVKEAKRYKNEYNLKKPLAEHINLTDYDNQVAQDTSSLINDGVKVQRTET } \\
\text { IKSNDINQLTVATDPHFNFEGDIKINGKKYDIKDQSVQLDTSNKEYKVEVNGVAKLKKDAEKDFLKDKTM } \\
\text { HLQLLFGQANRQDEPNDKKATSVVDVTLNHNLDGRLSKDALSQQLSALSRFDAHYKMYTDTKGREDKPFD } \\
\text { NKRLIDMMVDQVINDMESFKDDKVAVLHQIDSMEENSDKLIDDILNNKKNTTKNKEDISKLIDQLENVKK } \\
\text { TFAEEPQEPK }\end{array}$ \\
\hline
\end{tabular}

six transmembrane $\alpha$-helices and contains an uncharacterized extracellular segment, which was identified in a molecularshaving experiment (Dreisbach et al., 2010). Here, we report the expression, purification and crystallization of a stable $48 \mathrm{kDa}$ domain covering most of the extracellular segment of EsaA.

\section{Materials and methods}

2.1. Protein expression, purification and biophysical characterization

2.1.1. Cloning of EsaA, EsaAex_1 and EsaAex_2. The pASK-IBA3C vector was linearized by PCR (primers X1/X2). After codon-optimization for Escherichia coli, the esaA gene and the fragment esaAex_1 (coding for amino acids 47-804, which correspond to the predicted soluble part of EsaA) were cloned into the linearized pASK-IBA3C vector using Phusion polymerase (Invitrogen) and In-Fusion cloning (Clontech) (primer pairs X3/X4 and X5/X6), respectively. All primers are listed in Table 1. The DNA segment corresponding to the proteolytic fragment of esaAex_1 (esaAex_2; amino acids 275689 ) was amplified using primer pair X7/X8. In-Fusion cloning was used to ligate the amplified esaAex_2 fragment into pET$16 \mathrm{~b}$ vector including a Tobacco etch virus (TEV) cleavage site to produce the construct pET-16b-HIS-TEV-esaAex_2 (primer pair X9/X10).

2.1.2. Expression and purification of EsaA and EsaAex_1. E. coli BL21 Star cells were transformed with either pASKIBA3C-esaA or pASK-IBA3C-esaAex_1 and were grown in LB medium supplemented with $25 \mu \mathrm{g} \mathrm{ml}^{-1}$ chloramphenicol. Protein expression was induced by the addition of anhydrotetracycline (AHT; IBA Life Sciences) to a final concentration of $2 \mu \mathrm{g} \mathrm{ml}^{-1}$ at an optical density $\left(\mathrm{OD}_{600}\right)$ of 0.6. Bacteria transformed with pASK-IBA3C-esaA were grown for $20 \mathrm{~h}$ at $18^{\circ} \mathrm{C}$, whereas bacteria transformed with pASK-IBA3CesaAex_1 were grown for $20 \mathrm{~h}$ at $26^{\circ} \mathrm{C}$. The bacteria were harvested by centrifugation $\left(4000 g, 4^{\circ} \mathrm{C}\right)$. The bacterial pellets were resuspended in $50 \mathrm{~m} M$ Tris- $\mathrm{HCl}$ pH 8.0, $300 \mathrm{mM} \mathrm{NaCl}$, $3 \mathrm{~m} M$ DTT and lysed by three passages through an EmulsiFlex-C3 homogenizer (Avestin).

For the purification of EsaA, the bacterial membranes were isolated by ultracentrifugation $\left(100000 \mathrm{~g}, 1 \mathrm{~h}, 4^{\circ} \mathrm{C}\right)$. The membrane fraction of EsaA was resuspended in $50 \mathrm{~m} M$ Tris$\mathrm{HCl} \mathrm{pH} 8.0,300 \mathrm{~m} M \mathrm{NaCl}, 3 \mathrm{~m} M$ dithiothreitol (DTT) and incubated in $0.5 \% n$-dodecyl- $\beta$-D-maltopyranoside (DDM) for $1 \mathrm{~h}$ at $4^{\circ} \mathrm{C}$. Insoluble material was removed by ultracentrifugation $\left(100000 \mathrm{~g}, 1 \mathrm{~h}, 4^{\circ} \mathrm{C}\right)$ and the supernatant was loaded onto a Strep-Tactin column (1 ml; IBA Life Sciences) equilibrated with $50 \mathrm{~m} M$ Tris- $\mathrm{HCl}$ pH $8.0,300 \mathrm{~m} M \mathrm{NaCl}$, $3 \mathrm{~m} M$ DTT, $0.05 \%$ DDM. The column was washed with equilibration buffer until the UV baseline was reached, followed by elution in the same buffer supplemented with $2.5 \mathrm{~m} M$ D-desthiobiotin. The peak fractions were collected and concentrated to a volume of $0.5 \mathrm{ml}$ using $100 \mathrm{kDa}$ centrifugal concentrators (Millipore). The sample was loaded onto a Superose 6 Increase column (GE Healthcare) equilibrated with $20 \mathrm{~m} M$ Tris- $\mathrm{HCl} \mathrm{pH} 8.0,150 \mathrm{~m} M \mathrm{NaCl}, 3 \mathrm{~m} M$ DTT, $0.05 \%$ DDM.

For the purification of EsaAex_1, the bacteria were disrupted as described above and the lysate was clarified by ultracentrifugation $\left(100000 \mathrm{~g}, 1 \mathrm{~h}, 4^{\circ} \mathrm{C}\right)$. The supernatant containing EsaAex_1 was loaded onto a Strep-Tactin column (1 ml; IBA Life Sciences) equilibrated with $50 \mathrm{~m} M$ Tris- $\mathrm{HCl}$ pH 8.0, $300 \mathrm{~m} M \mathrm{NaCl}, 3 \mathrm{~m} M$ DTT. The column was washed with equilibration buffer until the UV baseline was reached, followed by elution in the same buffer supplemented with $2.5 \mathrm{~m} M$ D-desthiobiotin. The peak fractions were collected and concentrated to a volume of $2 \mathrm{ml}$ using $10 \mathrm{kDa}$ centrifugal concentrators (Millipore). The sample was loaded onto a Sepharose 300 column (GE Healthcare) equilibrated with $20 \mathrm{~m} M$ Tris- $\mathrm{HCl}$ pH 8.0, $150 \mathrm{~m} M \mathrm{NaCl}, 3 \mathrm{~m} M$ DTT. The peak fractions were concentrated using a $10 \mathrm{kDa}$ concentrator and used in proteolysis experiments. 
2.1.3. Expression and purification of EsaAex_2. For the purification of EsaAex_2, E. coli BL21 Star cells harboring pET-16b-esaAex_2 were grown in Luria-Bertani medium supplemented with $100 \mu \mathrm{g} \mathrm{ml}^{-1}$ ampicillin at $37^{\circ} \mathrm{C}$. Protein expression was induced by the addition of isopropyl $\beta$-D-1thiogalactopyranoside (IPTG) to a final concentration of $1 \mathrm{~m} M$ at an $\mathrm{OD}_{600}$ of 0.6 . The bacteria were grown for $16 \mathrm{~h}$ at $26^{\circ} \mathrm{C}$ and harvested by centrifugation $(4000 \mathrm{~g}, 15 \mathrm{~min})$. The bacterial pellet was resuspended in buffer $A(50 \mathrm{~m} M$ Tris- $\mathrm{HCl}$ $\mathrm{pH} 8,150 \mathrm{~m} M \mathrm{NaCl})$. The bacteria were disrupted as described above and the cell debris was removed by ultracentrifugation $\left(100000 \mathrm{~g}, 1 \mathrm{~h}, 26^{\circ} \mathrm{C}\right)$. The supernatant was supplemented with $20 \mathrm{~m} M$ imidazole and loaded onto a HisTrap HP column (GE Healthcare) equilibrated with buffer $A$. A wash step was applied using $20 \%$ buffer $B(50 \mathrm{~m} M$ Tris- $\mathrm{HCl} \mathrm{pH} 8,250 \mathrm{~m} M$ imidazole) until the UV absorbance reached the baseline before step elution with $100 \%$ buffer $B$. The His tag was then cleaved using TEV protease (1:10). The sample was dialyzed in buffer $A$, applied onto a $5 \mathrm{ml} \mathrm{Ni-NTA}$ column and the flowthrough was collected. EsaAex_2 was concentrated to a volume of $2 \mathrm{ml}$ using a Millipore centrifugation device (10 kDa cutoff) and subjected to size-exclusion chromatography using a Sephacryl 300 column equilibrated with buffer $C(150 \mathrm{~m} M \mathrm{NaCl}, 20 \mathrm{~m} M$ Tris- $\mathrm{HCl} \mathrm{pH}$ 8).

2.1.4. Limited proteolysis of EsaAex 1. The extracellular domain of EsaA (EsaAex_1; amino acids 47-804) was purified and subjected to limited proteolysis. $150 \mu \mathrm{g}$ EsaAex_1 was incubated with $1.5 \mu \mathrm{g}$ trypsin for $1 \mathrm{~h}$ at room temperature. Samples were taken every $15 \mathrm{~min}$ and the reaction was stopped with $3 \times$ protease-inhibitor cocktail (Roche). The samples were analyzed by SDS-PAGE. The protein band at $48 \mathrm{kDa}$ was excised and sent for mass-spectrometric analysis.

2.1.5. Analysis of the proteolysed EsaAex_1 by Nano LC-MS/MS. After limited proteolysis, the proteolytic fragments were resolved by SDS-PAGE and Coomassie-stained and the EsaAex_1 band was excised. The excised gel band was destained with $30 \%$ acetonitrile in $0.1 \mathrm{M}$ ammonium bicarbonate $\mathrm{pH} 8$, shrunk with $100 \%$ acetonitrile and dried in a vacuum concentrator (Concentrator 5301, Eppendorf, Germany). Digests were performed with $0.1 \mu \mathrm{g}$ elastase per gel band overnight at $37^{\circ} \mathrm{C}$ in $0.1 \mathrm{M}$ ammonium bicarbonate $\mathrm{pH}$ 8. After removing the supernatant, the peptides were extracted from the gel slices with $5 \%$ formic acid and the extracted peptides were pooled with the supernatant.

Nano LC-MS/MS analyses were performed on an Orbitrap Fusion (Thermo Scientific) equipped with an EASY-Spray ion source and coupled to an EASY-nLC 1000 (Thermo Scientific). The peptides were loaded onto a trapping column $(2 \mathrm{~cm}$ $\times 75 \mu \mathrm{m}$ internal diameter, PepMap C18, $3 \mu \mathrm{m}$ particles, $100 \AA$ pore size) and separated on an EASY-Spray column $(25 \mathrm{~cm} \times 75 \mu \mathrm{m}$ internal diameter, PepMap C18, $2 \mu \mathrm{m}$ particles, $100 \AA$ A pore size) with a 30 min linear gradient from $3 \%$ to $30 \%$ acetonitrile and $0.1 \%$ formic acid.

Both MS and MS/MS scans were acquired in the Orbitrap analyzer with resolutions of 60000 for MS scans and 15000 for MS/MS scans. HCD fragmentation with $35 \%$ normalized collision energy was applied. A top speed data-dependent
MS/MS method with a fixed cycle time of $3 \mathrm{~s}$ was used. Dynamic exclusion was applied with a repeat count of 1 and an exclusion duration of $30 \mathrm{~s}$; singly charged precursors were excluded from selection. The minimum signal threshold for precursor selection was set to 50000 . Predictive automated gain control (AGC) was used with AGC target values of $2 \times$ $10^{5}$ for MS scans and $5 \times 10^{4}$ for MS/MS scans. EASY-IC was used for internal calibration.

Database searching was performed against a custom database containing the protein sequence of interest with the PEAKS 8.0 software (Bioinformatics Solutions) using the following parameters: parent mass tolerance, 8 p.p.m.; fragment mass tolerance, $0.02 \mathrm{Da}$; enzyme, none; variable modifications, oxidation (M), pyroglutamate (N-terminal $\mathrm{Q}$ ), protein $\mathrm{N}$-terminal acetylation. Results were filtered to a $1 \%$ peptide-to-spectrum match false-discovery rate by the targetdecoy approach.

2.1.6. Size-exclusion chromatography-multi-angle light scattering (SEC-MALS) of EsaAex_2. SEC-MALS experiments were performed on a Superdex 200 10/300 GL column (GE Healthcare) coupled to a Dawn 8+ MALS detector and an Optilab T-rEX refractive-index detector (Wyatt Technology, Santa Barbara, California, USA). The column was equilibrated with $150 \mathrm{~m} M \mathrm{NaCl}, 20 \mathrm{~m} M$ Tris- $\mathrm{HCl} \mathrm{pH} 8.0$, $3 \mathrm{~m} M$ DTT. EsaAex_2 was concentrated to $4 \mathrm{mg} \mathrm{ml}^{-1}$ and a sample volume of $100 \mu \mathrm{l}$ was loaded onto the column. Sizeexclusion chromatography was run at a flow rate of $0.5 \mathrm{ml} \mathrm{min}^{-1}$. The molecular mass of EsaAex_2 was determined using the ASTRA 6 software (Wyatt Technology).

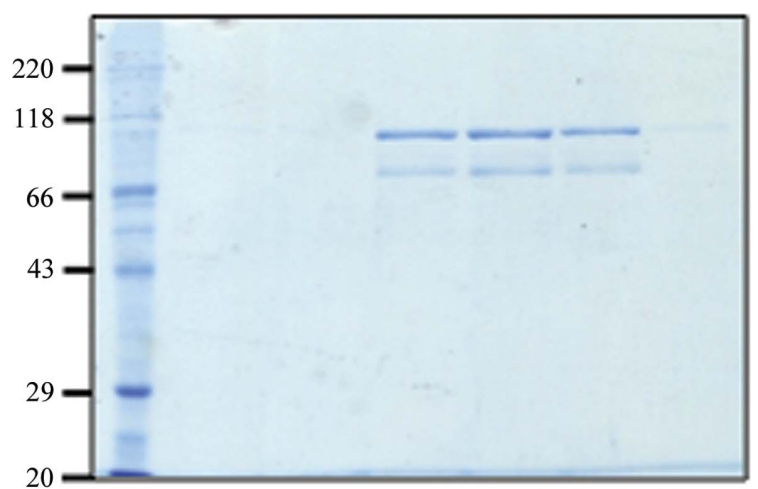

(a)

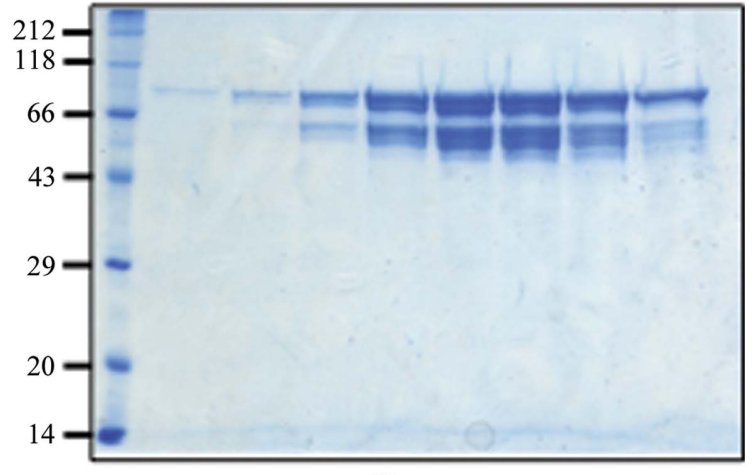

(b)

Figure 1

SDS-PAGE of (a) EsaA and (b) EsaAex_1 after size-exclusion chromatography. Molecular-mass markers are labeled in $\mathrm{kDa}$. 
2.1.7. Circular dichroism (CD) and thermal unfolding experiments. CD spectroscopy was performed using a Jasco J810 spectropolarimeter. Spectra were recorded from 195 to $260 \mathrm{~nm}$ at a scanning speed of $50 \mathrm{~nm} \mathrm{~min}{ }^{-1}$ with a response time of $2 \mathrm{~s}$ and a band width of $1 \mathrm{~nm}$ at $4{ }^{\circ} \mathrm{C}$. Thermal unfolding experiments of EsaAex_2 were conducted at $224 \mathrm{~nm}$ (bandwidth $2 \mathrm{~nm}$, response time $16 \mathrm{~s}$ ) starting at $4^{\circ} \mathrm{C}$ and heating to $70^{\circ} \mathrm{C}$ (at a heating rate of $1 \mathrm{~K} \mathrm{~min}^{-1}$ ). $5 \mu M$ EsaAex_2 in $50 \mathrm{~m} M$ phosphate buffer $\mathrm{pH} 8.0$ was used.

\subsection{Crystallization}

After size-exclusion chromatography, the purest peak fractions of EsaAex_2 were pooled and concentrated to $5 \mathrm{mg} \mathrm{ml}^{-1}$ using centrifugal concentrators (Millipore, $10 \mathrm{kDa}$ cutoff). $1.5 \mu \mathrm{l}$ protein solution and $1.5 \mu \mathrm{l}$ reservoir solution were mixed in a 1:1 ratio and placed on $22 \mathrm{~mm}$ circular siliconized cover slides (Jena Bioscience). Hanging-drop crystallization experiments were performed in Crystalgen plates using a reservoir volume of $600 \mu \mathrm{l}$. Crystals appeared after 4-5 days and grew to dimensions of $\sim 0.2 \times 0.2 \mathrm{~mm}$. Before flash-cooling, crystals were cooled to $4^{\circ} \mathrm{C}$ in their mother liquor for $24 \mathrm{~h}$. Pre-cooled reservoir solution containing $25 \%$ glycerol was added gradually to the crystals until a final concentration of $25 \%(v / v)$ glycerol was reached in
Table 2

Crystallization.

\begin{tabular}{ll}
\hline Method & Hanging drop \\
Temperature (K) & 293 \\
Plate type & Crystalgen \\
Protein concentration $\left(\mathrm{mg} \mathrm{ml}^{-1}\right)$ & 5 \\
$\begin{array}{l}\text { Buffer composition of protein } \\
\text { solution }\end{array}$ & $150 \mathrm{~m} M \mathrm{NaCl}, 20 \mathrm{~m} M$ Tris- $\mathrm{HCl} \mathrm{pH} 8.0$ \\
Composition of reservoir solution & $0.2 M$ ammonium citrate tribasic pH 7.0, \\
& $16 \%$ PEG 3350 \\
Volume and ratio of drop & $3 \mu \mathrm{l}(1: 1$ ratio $)$ \\
Volume of reservoir $(\mu \mathrm{l})$ & 600 \\
\hline
\end{tabular}

the crystallization drop, and the crystals were flash-cooled in liquid nitrogen. Crystallization information is summarized in Table 2.

\subsection{Data collection and processing}

Crystals of EsaAex_2 were flash-cooled in liquid nitrogen and diffraction experiments were performed on beamline ID30-A3 at the European Synchrotron Radiation Facility (ESRF). The beam transmission was set to $25.2 \%$. The collected data were processed using the XDS software package (Kabsch, 2010). POINTLESS from the CCP4 package (Winn et al., 2011) was used for space-group determination (Evans, 2006). The Matthews coefficient (Matthews,

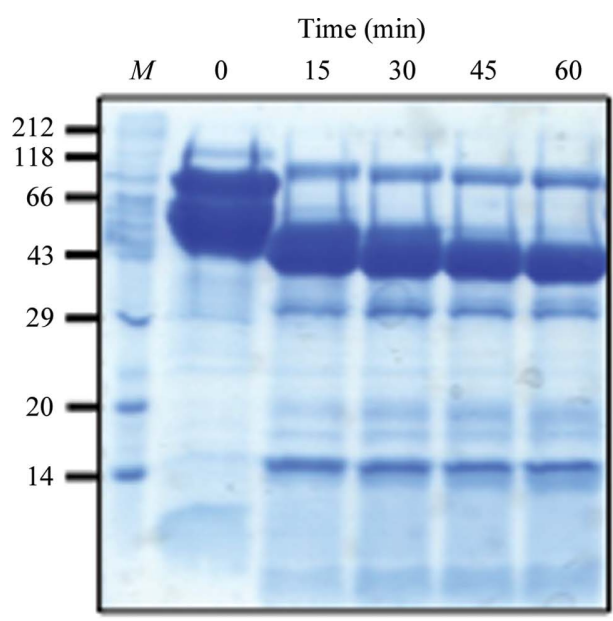

(a)

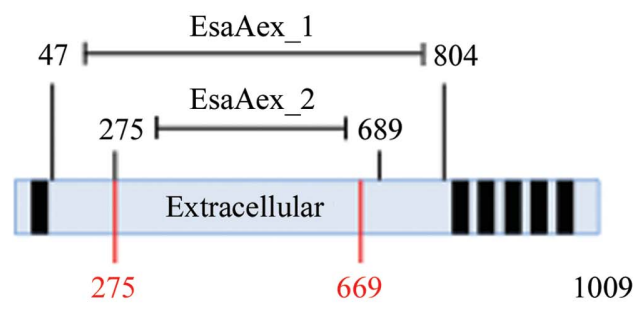

Figure 2

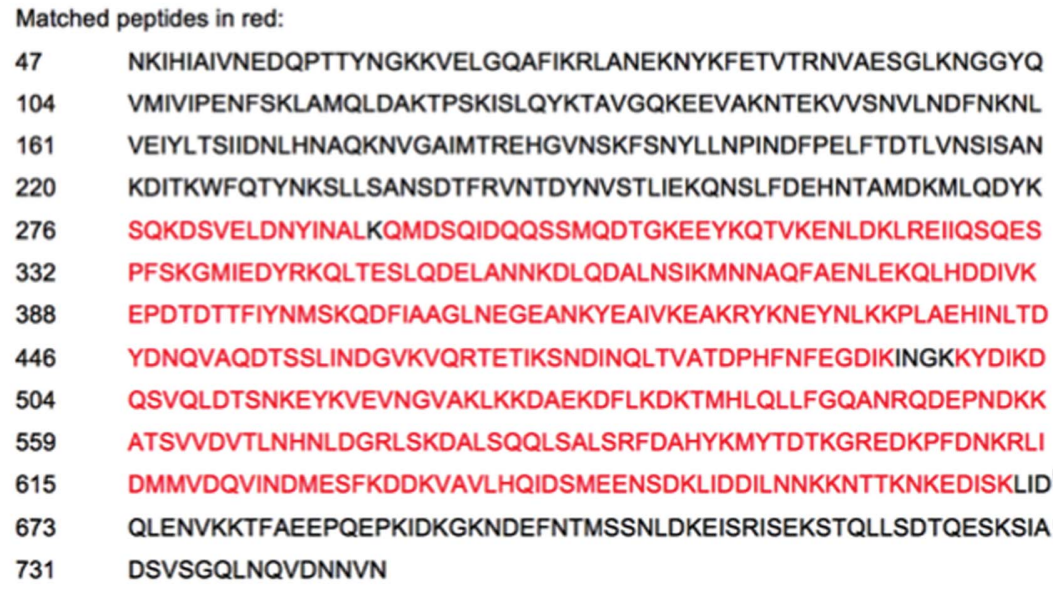

(b)

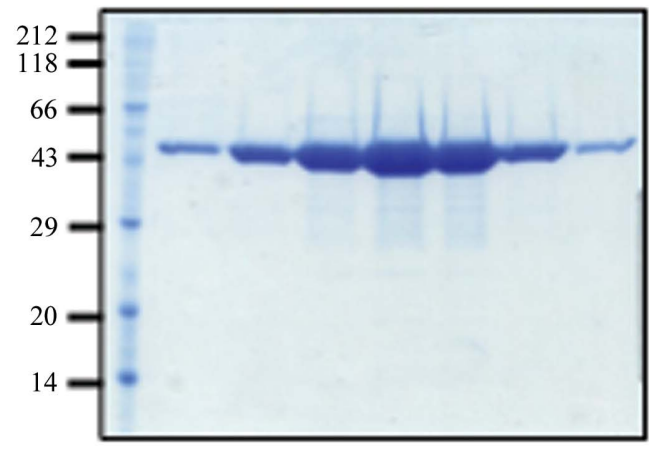

$(d)$

(a) SDS-PAGE analysis of EsaAex_1 after limited proteolysis. Lane $M$ contains molecular-mass markers (labeled in kDa). (b) Sequence of EsaAex_1: the peptide coverage detected by fingerprint mass spectrometry (red) indicates the protein boundaries of the excised band at $43 \mathrm{kDa}$. (c) Schematic of the full-length EsaA protein showing the EsxAex_1 and EsaAex_2 boundaries and the MS fingerprint (red). (d) SDS-PAGE of EsaAex_2 after sizeexclusion chromatography. Molecular-mass markers are labeled in $\mathrm{kDa}$. 
1968) and the solvent content were calculated using MATTHEWS_COEF. Attempts to solve the structure by molecular replacement failed.

\section{Results and discussion}

Purified full-length EsaA (amino acids 1-1009) and the variant EsaAex_1 (amino acids 47-804), which composed the predicted soluble part of the membrane protein, showed similar degradation patterns (Figs. $1 a$ and $1 b$ ). In order to identify a stable protein core, EsaAex_1 was subjected to limited proteolysis (Fig. 2a). After the addition of trypsin, samples were taken over the course of $1 \mathrm{~h}$. SDS-PAGE analysis showed a stable proteolytic product of $\sim 48 \mathrm{kDa}$ (Fig. 2a). The boundaries of the protein fragment were determined by fingerprint mass spectrometry (amino acids 275-669; Fig. 2b) and matched an extracellular segment of EsaA which was identified in molecular-shaving experiments of whole cells from different $S$. aureus strains (Dreisbach et al., 2010). Since no crystals of this fragment (amino acids 275-669) could be obtained, a variant (EsaAex_2; amino acids 275-689) was cloned which preserved a predicted $\alpha$-helix (597-683) at the C-terminus and was purified to homogeneity using nickelaffinity and size-exclusion chromatography (Figs. $2 c$ and $2 d$ ).

Octahedral crystals of EsaAex_2 were grown in hanging drops at $293 \mathrm{~K}$ (Fig. 3a). However, the diffraction of these crystals varied strongly and was limited to $\sim 5 \AA$ resolution. Cooling the crystals to $4^{\circ} \mathrm{C} 24 \mathrm{~h}$ before flash-cooling improved the diffraction of some, but not all, crystals to $4.0 \AA$ resolution (Fig. 3b; Table 3). The crystals belonged to the enantiomorphic
Table 3

Data collection and processing.

Values in parentheses are for the outer shell.

\begin{tabular}{ll}
\hline Diffraction source & ID30-A3, ESRF \\
Wavelength $(\AA)$ & 0.9677 \\
Temperature $(\mathrm{K})$ & 100 \\
Detector & EIGER 4M \\
Crystal-to-detector distance $(\mathrm{mm})$ & 308.7 \\
Rotation range per image $\left({ }^{\circ}\right)$ & 0.05 \\
Total rotation range $\left({ }^{\circ}\right)$ & 180 \\
Exposure time per image $(\mathrm{s})$ & 0.02 \\
Space group & $P 4_{1} 2_{2} 2$ or $P 4_{3} 2{ }_{1} 2$ \\
$a, b, c(\AA)$ & $197.544,197.544,368.334$ \\
$\alpha, \beta, \gamma\left({ }^{\circ}\right)$ & $90,90,90$ \\
Mosaicity $\left({ }^{\circ}\right)$ & 0.09 \\
Resolution range $(\AA)$ & $20.0-4.0$ \\
Total No. of reflections & 1003682 \\
No. of unique reflections & 72074 \\
Completeness $(\%)$ & $98.6(97.0)$ \\
Multiplicity & 13.84 \\
$\langle I / \sigma(I)\rangle$ & $9.74(0.98) \dagger$ \\
$R_{\text {meas }}(\%)$ & $23.9(276.4)$ \\
Overall $B$ factor from Wilson plot $\left(\AA^{2}\right)$ & 153.1
\end{tabular}

$\dagger \mathrm{CC}_{1 / 2}$ is $41.6 \%$ in the outer shell, indicating that the data contain signal. $I / \sigma(I)$ falls below 2.0 at $4.2 \AA$ resolution.

tetragonal space group $P 4_{1} 2_{1} 2$ or $P 4_{3} 2_{1} 2$, with unit-cell parameters $a=197.5, b=197.5, c=368.3 \AA, \alpha=\beta=\gamma=90^{\circ}$. Based on Matthews coefficient calculations $\left(V_{\mathrm{M}}=2.34 \AA^{3} \mathrm{Da}^{-1}\right.$; solvent content $47.55 \%)$, there are 16 molecules in the asymmetric unit (Matthews, 1968). Attempts to solve the structure by molecular replacement failed owing to a lack of homologous structures. Heavy metal atom screens are currently being carried out to obtain phases.
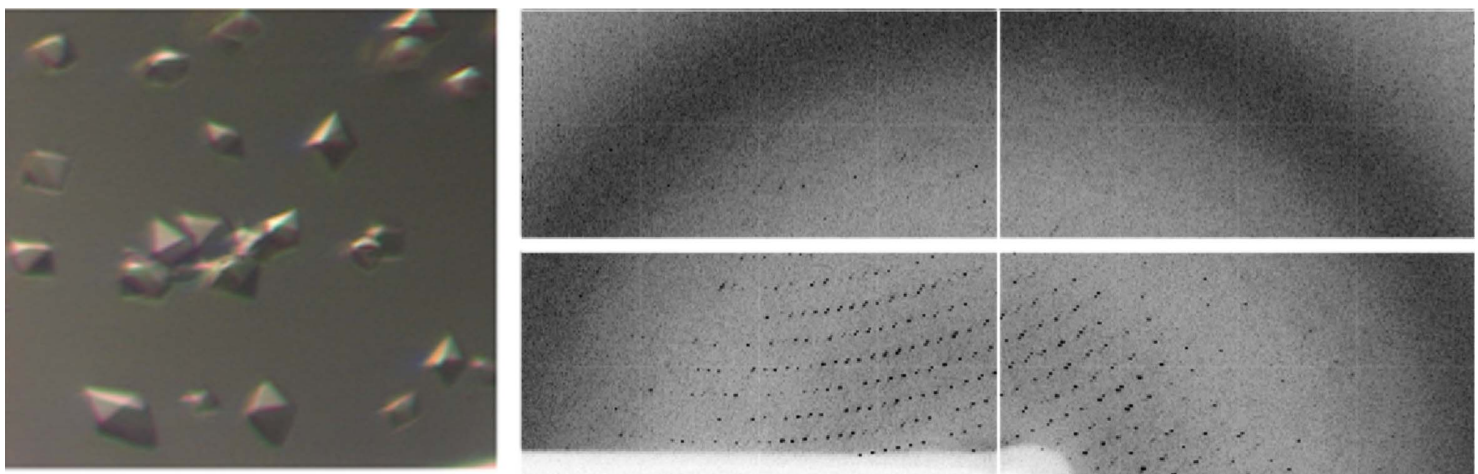

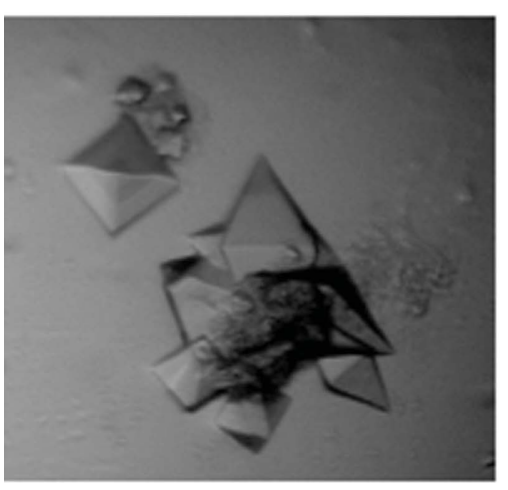

(a)
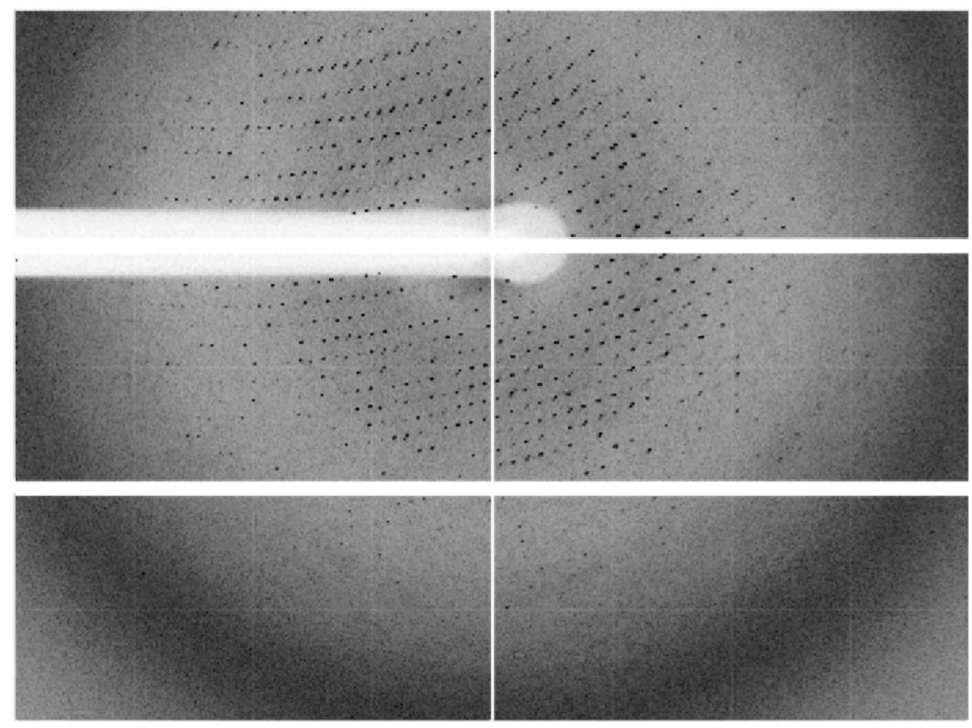

(b)

Figure 3

(a) Octahedral crystals and (b) diffraction image of EsaAex_2. 


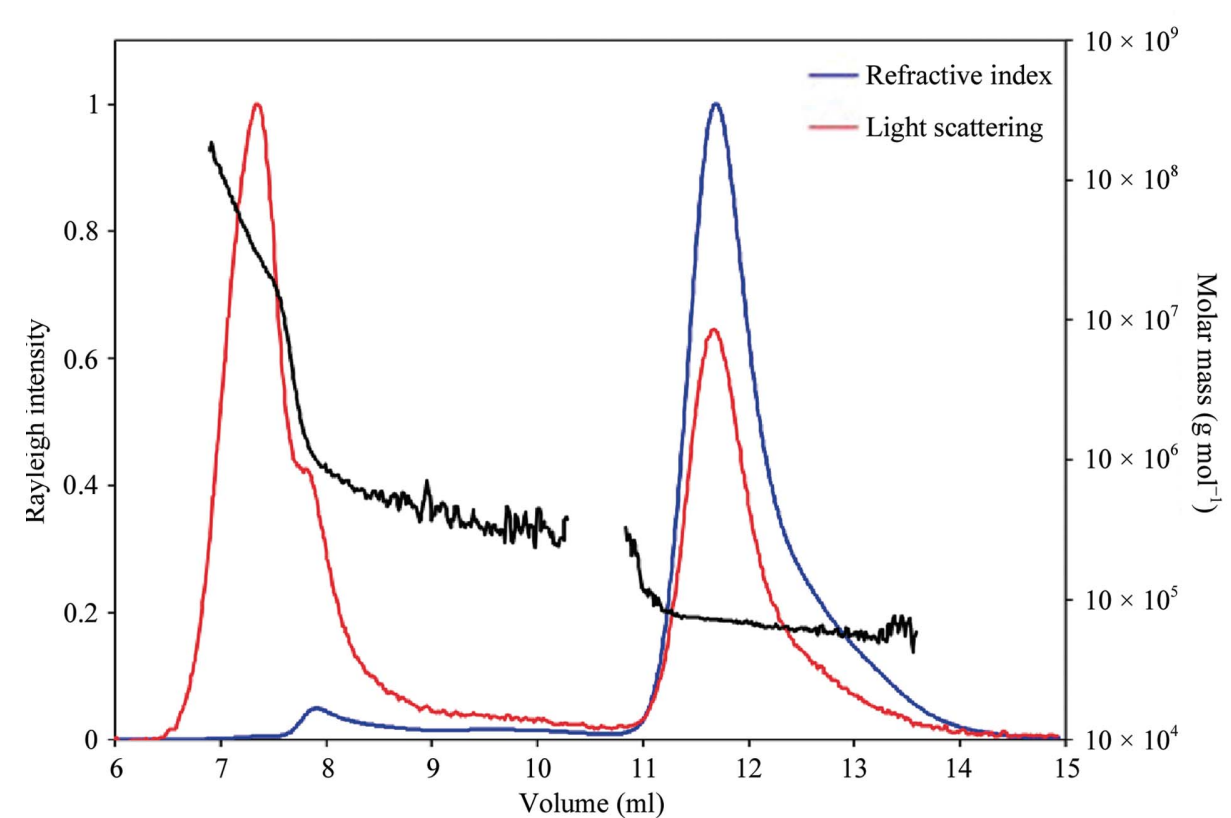

(a)

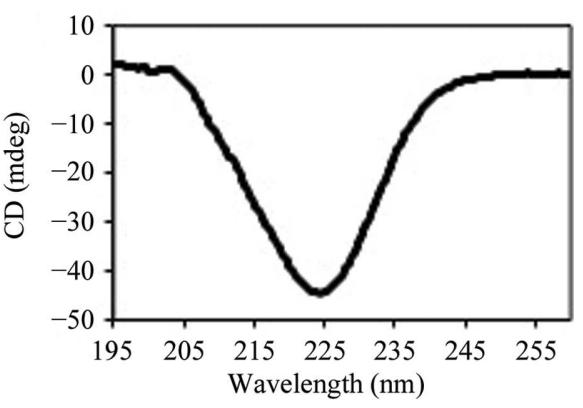

(b)

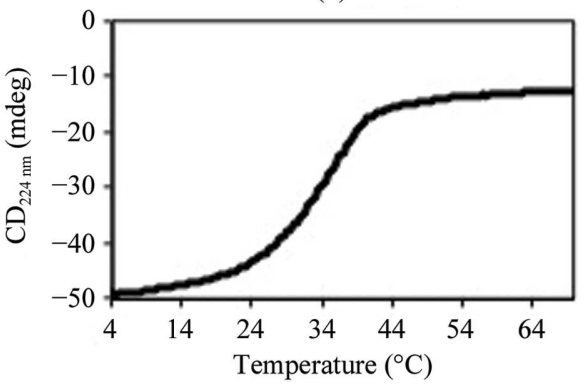

(c)

Figure 4

Biophysical characterization of EsaAex_2. (a) SEC-MALS analysis using a Superdex 200 10/300 GL column, (b) CD spectrum and (c) melting curve.

Size-exclusion chromatography combined with multi-angle light scattering indicated the formation of a dimer (Fig. 4a). Circular dichroism spectroscopy revealed that EsaAex_2 contains $70 \% \alpha$-helices and $4 \% \beta$-sheets (Perez-Iratxeta \& Andrade-Navarro, 2008; Fig. 4b). Melting-curve analysis showed a single transition, suggesting that the extracellular fragment is a single domain with a melting temperature of $34.5^{\circ} \mathrm{C}$ (Fig. $4 c$ ).

\section{Acknowledgements}

We acknowledge the European Synchrotron Radiation Facility for the provision of synchrotron-radiation facilities and we would like to thank the local contacts for assistance in using beamline ID30-A3. We thank Stephanie Lamer for acquiring MS data (AG Schlosser, University of Würzburg).

\section{Funding information}

Funding for this research was provided by: Elite Network of Bavaria (grant No. N-BM-2013-246 to Sebastian Geibel).

\section{References}

Ahmed, M. M., Aboshanab, K. M., Ragab, Y. M., Missiakas, D. M. \& Aly, K. A. (2018). Arch. Microbiol. 200, 1075-1086.
Aly, K. A., Anderson, M., Ohr, R. J. \& Missiakas, D. (2017). J. Bacteriol. 199, e00482-17.

Burts, M. L., Williams, W. A., DeBord, K. \& Missiakas, D. M. (2005). Proc. Natl Acad. Sci. USA, 102, 1169-1174.

Dreisbach, A., Hempel, K., Buist, G., Hecker, M., Becher, D. \& van Dijl, J. M. (2010). Proteomics, 10, 3082-3096.

Evans, P. (2006). Acta Cryst. D62, 72-82.

Gröschel, M. I., Sayes, F., Simeone, R., Majlessi, L. \& Brosch, R. (2016). Nat. Rev. Microbiol. 14, 677-691.

Kabsch, W. (2010). Acta Cryst. D66, 125-132.

Kneuper, H., Cao, Z. P., Twomey, K. B., Zoltner, M., Jäger, F., Cargill, J. S., Chalmers, J., van der Kooi-Pol, M. M., van Dijl, J. M., Ryan, R. P., Hunter, W. N. \& Palmer, T. (2014). Mol. Microbiol. 93, 928943.

Matthews, B. W. (1968). J. Mol. Biol. 33, 491-497.

Mielich-Süss, B., Wagner, R. M., Mietrach, N., Hertlein, T., Marincola, G., Ohlsen, K., Geibel, S. \& Lopez, D. (2017). PLoS Pathog. 13, e1006728.

Perez-Iratxeta, C. \& Andrade-Navarro, M. A. (2008). BMC Struct. Biol. 8, 25.

Unnikrishnan, M., Constantinidou, C., Palmer, T. \& Pallen, M. J. (2017). Trends Microbiol. 25, 192-204.

Winn, M. D., Ballard, C. C., Cowtan, K. D., Dodson, E. J., Emsley, P., Evans, P. R., Keegan, R. M., Krissinel, E. B., Leslie, A. G. W., McCoy, A., McNicholas, S. J., Murshudov, G. N., Pannu, N. S., Potterton, E. A., Powell, H. R., Read, R. J., Vagin, A. \& Wilson, K. S. (2011). Acta Cryst. D67, 235242 . 